\title{
Vascular flow on doppler sonography may not be a valid characteristic to distinguish colloid nodules from papillary thyroid carcinoma even when accounting for nodular size
}

\author{
J. Matthew Debnam ${ }^{1}$, Thinh Vuㄹ, Jia Sun ${ }^{2}$, Wei Wei ${ }^{2}$, Savitri Krishnamurthy ${ }^{3}$, Mark E. Zafereo ${ }^{4}$, \\ Steven P. Weitzman ${ }^{5}$, Naveen Garg ${ }^{6}$, Salmaan Ahmed ${ }^{1}$
}

${ }^{1}$ Department of Diagnostic Radiology, Section of Neuroradiology, ${ }^{2}$ Department of Biostatistics, ${ }^{3}$ Department of Pathology, ${ }^{4}$ Department of Head and Neck Surgery, ${ }^{5}$ Department of Endocrine Neoplasia \& Hormonal Disorders, ${ }^{6}$ Department of Diagnostic Radiology, Section of Abdominal Imaging, The University of Texas MD Anderson Cancer Center, Houston, TX, USA

Contributions: (I) Conception and design: All authors; (II) Administrative support: None; (III) Provision of study materials or patients: All authors; (IV) Collection and assembly of data: All authors; (V) Data analysis and interpretation: All authors; (VI) Manuscript writing: All authors; (VII) Final approval of manuscript: All authors.

Correspondence to: J. Matthew Debnam, MD. The University of Texas MD Anderson Cancer Center, 1400 Pressler Blvd., Unit 1482, Houston, TX, USA. Email: Matthew.Debnam@mdanderson.org.

\begin{abstract}
Background: The purpose of this study was to test the hypothesis that there is no significant difference in vascular flow patterns between cytopathologically-proven colloid nodules and papillary thyroid carcinoma (PTC) even when adjusting for nodule size.

Methods: Doppler vascular flow patterns in 200 colloid nodules and 166 nodules with PTC were retrospective reviewed independently by 2 neuroradiologists blinded to the cytopathological results. Absence of vascular flow, perinodular and/or intranodular flow, and diffuse vascular flow were recorded. The vascular flow patterns were compared without (Fisher exact test) and with (Kruskal-Wallis test) an adjustment for nodular size. Using the most common flow pattern as the reference group, multiple logistic regression was used to compare the flow patterns. Sample skewness was calculated to determine degree of symmetry of the size distribution for each vascular flow category.

Results: No significant difference was found in the tested vascular flow patterns between colloid nodules and PTC both without and with an adjustment for nodular size $(\mathrm{P}>0.05)$. Intranodular flow only was the largest group ( $\mathrm{n}=111 / 366)$ and used as the reference for multiple logistic regression. No significant difference was noted between the vascular flow patterns $(\mathrm{P}>0.05)$. Sample skewness showed that nodules were generally smaller in size with outliers of larger size on the opposite end of the spectrum.

Conclusions: Independent of nodule size the absence or presence of vascular flow is not significantly different between colloid nodules and PTC. Therefore, vascular flow may not be useful in distinguishing between colloid nodules and PTC.
\end{abstract}

Keywords: Doppler ultrasonography; neoplasms; thyroid gland

Submitted Dec 30, 2018. Accepted for publication Aug 14, 2019.

doi: 10.21037 /gs.2019.08.06

View this article at: http://dx.doi.org/10.21037/gs.2019.08.06

\section{Introduction}

Sonography is the primary imaging modality used to assess thyroid nodules (1-3). A component of the sonographic assessment is high-frequency color and power Doppler sonography which permits dynamic evaluation of thyroid nodules. Color Doppler measures the velocity and direction of blood moving through the sampled tissue; however, this technique is limited by noise and is angle dependent. 
Power Doppler measures the total amount of blood flow but does not provide information about direction. When a suspicious nodule is detected, ultrasound (US)-guided fine-needle aspiration (FNA) can be performed following the US examination, allowing immediate histopathologic correlation. In experienced hands, US-guided FNA is innocuous and accurate (4-6).

The 2015 revised guidelines of the American Thyroid Association state that the sonographic report of thyroid nodule should include "nodule size (in 3 dimensions) and location (e.g., right upper lobe) and a description of the nodule's sonographic features including composition (solid, cystic proportion, or spongiform), echogenicity, margins, presence and type of calcifications, and shape if taller than wide, and vascularity." (7). In the past, studies equated the presence of vascularity (vascular flow) with malignancy whereas the 2015 revised American Thyroid Association guidelines suggest (and other studies have shown) that the presence of vascularity is not a "robust" risk factor for thyroid malignancy (7-9).

In our experience, independent of nodule size, subsets of both FNA-proven colloid nodules and FNA-proven papillary thyroid carcinomas (PTCs) exhibit intranodular and/or perinodular vascular flow on Doppler sonography. Although there are data comparing vascular flow in benign as opposed to malignant thyroid nodules, to the best of our knowledge there are no reports in the literature specifically comparing vascular flow in cytopathologicallyproven colloid nodules and PTC, and there are no reports that have adjusted for nodule size. We hypothesized that there are no significant differences in color or power Doppler flow characteristics between colloid nodules and PTC even when making an adjustment for nodule size. In order to test this hypothesis, we compared the absence or presence of intranodular and perinodular vascular flow in cytopathologically-proven nodules containing colloid and nodules with cytopathologically-proven PTC and evaluated the aforementioned flow patterns after making an adjustment for nodule size.

\section{Methods}

The Institutional Review Board of The University of Texas MD Anderson Cancer Center approved this study and waived the requirement for informed consent. Data review was performed in compliance with all applicable Health Insurance Portability and Accountability Act regulations. An institutional database was retrospectively reviewed to identify consecutive patients with cytopathologically documented colloid nodules and PTC seen at our institution. These patients' demographic and clinical characteristics and US findings were reviewed. For a patient to be included in the study, US-guided FNA or surgical resection had to show that the thyroid nodule had cytopathologic features consistent with a colloid nodule or PTC. Exclusion criteria included FNA results recorded as "suspicious" or "indeterminate" with lack of pathologic correlation from surgical biopsy or thyroidectomy. Sixteen colloid nodules and 34 nodules with PTC did not meet these criteria and were excluded.

Color or power Doppler sonography was performed utilizing a high-frequency linear-array transducer (7-14 $\mathrm{MHz}$ ) with color and power Doppler capabilities attached to an alpha-10 scanner (Hitachi-Aloka, Tokyo, Japan). The following patterns of vascular flow on color or power Doppler sonography were assessed: (I) absence of vascular flow; (II) perinodular flow, defined as flow in $>25 \%$ of the circumference of the nodule; (III) intranodular flow; and/ or (IV) diffuse flow, a subset of intranodular flow. From this group the nodules with both intranodular and perinodular flow were recorded a as a fifth category.

A retrospective review of the US studies, including color or power Doppler studies, were conducted separately by 2 neuroradiologists (Thinh $\mathrm{Vu}$ and Salmaan Ahmed), each with over 10 years of head and neck sonography experience, who were blinded to the cytologic or pathologic results. If there was a disagreement, then consensus results were used for data analyses. Interobserver variability between two reviewers were determined for each vascular pattern using Kappa statistics with $95 \%$ confidence intervals.

Patient demographics, indications for sonography, vascular flow patterns, and nodule size were summarized using frequencies, percentages, means, standard deviations (SD), medians, and range by disease status (PTC and colloid). First, Welch's $t$-test was used to compare the nodule sizes between PTC and colloid nodules. Second, we performed the Fisher exact test to compare the vascular flow patterns between PTC and colloid without an adjustment for the size of the nodules. Third, the Kruskal-Wallis test was used to compare the nodule sizes among different vascular flow patterns within the colloid group and the PTC group separately. Fourth, to evaluate the association of the vascular flow patterns with nodule type, the category of flow patterns with the largest sample size in the total group of 366 nodules was used as a reference group for multiple logistic regression with an adjustment for nodule 
size. Finally, Pearson's moment of skewness was calculated to determine degree of symmetry of the size distribution for each vascular flow category. Skewness measures the extent to which the distribution of variables lies on any side of the mean of the variable. In positive skewness the mode is smaller than the mean and in negative skewness the mode is greater than the mean. All tests were two-sided and $\mathrm{P}$ values of 0.05 or less were considered statistically significant.

Table 1 Patient demographics and indications for sonography

\begin{tabular}{lcc}
\hline Characteristic & $\begin{array}{c}\text { Colloid nodule } \\
(\mathrm{n}=200)\end{array}$ & $\begin{array}{c}\mathrm{PTC} \\
(\mathrm{n}=166)\end{array}$ \\
\hline Female/male ratio & $155 / 45$ & $118 / 48$ \\
Median age (SD), years & $58[14]$ & $53[16]$ \\
Indication for sonography & 177 & 109 \\
Palpable thyroid nodule & 0 & 22 \\
Biopsy findings of concern (OSH) & 13 & 9 \\
CT abnormality & 2 & 10 \\
PET/CT uptake & 3 & 1 \\
MRI abnormality & 0 & 11 \\
Cancer screening & 3 & 2 \\
HPT & 1 & 1 \\
Hoarseness & 1 & 1 \\
Neck discomfort & $144 / 56$ & $154 / 12$ \\
Power/color Doppler ratio & & $1.9 \pm 1.1$ \\
Nodular size & $2.3 \pm 1.5$ & $(0.4,5.9)$ \\
Mean \pm SD (P<0.05) & $(0.5,9.8)$ & \\
Median (min, max) & & \\
\hline
\end{tabular}

OSH, outside hospital; CT, computed tomography; PET, positron emission tomography; MRI, magnetic resonance imaging; HPT, hyperparathyroidism; PTC, papillary thyroid carcinoma.
Statistical analysis was carried out using SAS version 9.4 (SAS Institute, Cary, NC, USA).

\section{Results}

Two hundred patients with colloid nodules and 166 patients with nodules with PTC were included in the study. A colloid nodule and a coincident nodule with PTC were present in a multinodular thyroid gland of 29 patients. As a result, these patients were included in both groups. The patient demographics, indications for US evaluation, type of Doppler (color $v s$. power) and nodular size are indicated in Table 1. The colloid nodule size ranged from 0.5 to $9.8 \mathrm{~cm}$ (mean, $2.3 \pm 1.5 \mathrm{~cm}$ ) and the nodules with PTC ranged from 0.4 to $5.9 \mathrm{~cm}(1.9 \pm 1.1 \mathrm{~cm})$. Welch's $t$-test showed nodules with PTC were significantly smaller than colloid $(\mathrm{P}<0.05)$.

\section{Interobserver variability}

Kappa statistics revealed almost perfect agreement in the assessment of absence of vascular flow $(0.9,0.85-0.96$; kappa $/ 95 \%$ confidence interval), perinodular $(0.86,0.81-$ $0.91)$, intranodular $(0.88,0.83-0.93)$ and diffuse flow $(0.88$, $0.77-1)$. The interobserver agreement is as follows: $<0$ poor; $0.01-0.20$ slight; $0.21-0.40$ fair; $0.41-0.60$ moderate; 0.61-080 substantial; 0.81-1.00 almost perfect.

\section{Vascular flow in colloid nodules}

The 200 patients with colloid nodules included 155 women and 45 men ranging in age from 14 to 85 years (mean, $55.4 \pm 14$ years). Vascular flow was absent in 30 nodules $(15 \%)$. Thirty $(15 \%)$ had perinodular flow. Fifty-eight nodules $(29 \%)$ had intranodular flow, which was diffuse in 14 nodules (7\%), and $68(34 \%)$ had both perinodular and intranodular flow. The US appearance of vascular flow in these colloid nodules is summarized in Table 2.

Table 2 Nodular vascular flow patterns and comparison with Fisher's exact test

\begin{tabular}{|c|c|c|c|c|}
\hline Flow pattern & Total $(\mathrm{N}=366)$ & Colloid (N=200) & PTC $(\mathrm{N}=166)$ & $P$ value \\
\hline Perinodular only & $56(15.3)$ & $30(15.0)$ & $26(15.7)$ & \\
\hline Intranodular only & $111(30.3)$ & $58(29.0)$ & 53 (31.9) & \\
\hline Diffuse & $20(5.5)$ & $14(7.0)$ & $6(3.6)$ & \\
\hline
\end{tabular}

Values presented as $\mathrm{N}(\%)$. PTC, papillary thyroid carcinoma. 
Table 3 Comparison of colloid nodule size among various flow patterns (Kruskal-Wallis test)



Table 4 Comparison of PTC nodule size among various flow patterns (Kruskal-Wallis test)

\begin{tabular}{lccccccc}
\hline Vascular flow pattern & Number & Mean $(\mathrm{cm})$ & Std Dev & Min $(\mathrm{cm})$ & Median $(\mathrm{cm})$ & Max $(\mathrm{cm})$ & $P$ value \\
\hline Absent & 38 & 1.52368 & 1.09061 & 0.5 & 1.15 & 5.4 & 0.0001 \\
Perinodular only & 26 & 1.49231 & 0.81237 & 0.4 & 1.35 & 3.8 \\
Intranodular only & 53 & 2.17359 & 1.05651 & 0.7 & 2 & 4.9 \\
Diffuse & 6 & 2.63333 & 1.10574 & 1.1 & 2.6 & 4.1 \\
Both intranodular and perinodular & 43 & 2.11628 & 1.11076 & 0.7 & 1.7 & 5.9 \\
\hline
\end{tabular}

PTC, papillary thyroid carcinoma.

\section{Vascular flow in PTC}

The 166 patients with a thyroid nodule diagnosed as PTC included 118 women and 48 men ranging in age from 14 to 88 years (mean, $51.6 \pm 16$ years). Vascular flow was absent in 38 nodules $(22.9 \%)$. Twenty-six nodules $(15.7 \%)$ had perinodular flow. Fifty-three nodules $(31.9 \%)$ had intranodular flow, which was diffuse in 6 nodules $(3.6 \%)$. Both perinodular and intranodular flow was present in 43 nodules $(25.9 \%)$. The US appearance of vascular flow in PTC is summarized in Table 2.

\section{Comparison of vascular flow patterns without nodule size adjustment (Fisher exact test)}

Without adjusting for nodular size, no significant difference was noted between the various vascular flow patterns for either colloid nodules or nodules with PTC $(\mathrm{P}=0.13)$. Table 2 summarizes these results.

\section{Comparison of size and vascular flow pattern (Kruskal- Wallis test)}

The size was not significantly different among all various vascular flow patterns in the colloid nodule group $(\mathrm{P}=0.98)$.
However, in the PTC nodule group, the group means of size were significantly different among some vascular flow patterns $(\mathrm{P}=0.0001)$. Tables 3 and 4 summarizes these results.

\section{Multiple logistic regression}

Intranodular flow had a sample size of $111 / 366$ and was used as the reference group for multiple logistic regression analysis. Only a smaller size nodule was significantly associated with PTC $(\mathrm{P}=0.0097)$. No significant difference was noted in the association between colloid or PTC and other vascular flow patterns after adjusting for nodule size $(\mathrm{P}>0.05)$ (Table 5).

\section{Skewness of size for each vascular flow category}

Except for diffuse flow in the PTC group (-0.05), the nodule size showed a positively skewed distribution (mode less than mean value) in the remaining categories of vascular flow for both colloid and PTC. The skewness of size for each category was as follows: absence of vascular flow (1.94, 1.97; colloid, PTC), perinodular (1.36, 1.32), intranodular $(1.46,0.85)$, both diffuse flow $(1.02,-0.05)$, and both perinodular and intranodular flow $(1.35,1.36)$. 
Table 5 Summary of multiple logistic regression predicting the probability of having PTC with intranodular only as the reference group

\begin{tabular}{|c|c|c|c|}
\hline Effect & Odds ratio & $95 \% \mathrm{Cl}$ & $P$ value \\
\hline Both intranodular and perinodular vs. intranodular only & 0.47 & $0.17-1.33$ & 0.16 \\
\hline Diffuse vs. intranodular only & 1.32 & $0.71-2.45$ & 0.38 \\
\hline No flow vs. intranodular only & 0.87 & $0.45-1.66$ & 0.66 \\
\hline \multicolumn{4}{|l|}{ Size } \\
\hline $1 \mathrm{~cm}$ increase & 0.8 & $0.68-0.95$ & 0.0097 \\
\hline
\end{tabular}

PTC, papillary thyroid carcinoma.

\section{Discussion}

This study provides important information about the Doppler sonographic appearance of thyroid nodules in the assessment for malignancy. Our findings did support our hypothesis that colloid nodules would demonstrate vascular flow patterns similar to that of PTC both without an adjustment for nodular size. This was confirmed without an adjustment for size using the Fisher exact test and with an adjustment for nodular size with the Kruskal-Wallis test. On multiple logistic regression using intranodular flow as the reference group, the association of nodule type with other flow patterns was not significantly different from the association with intranodular flow only after adjusting for size. The only significant different finding in our study was that the PTC nodules were significantly smaller that colloid nodules.

In our study, absence of both intranodular and perinodular flow was more common in nodules with PTC (no flow in $23 \%$ ) than in colloid nodules (no flow in 15\%), but this was not significantly different $(\mathrm{P}>0.05)$. Even when adjusting for differences in nodular size, the absence of vascular flow was not significantly different $(\mathrm{P}>0.05)$. Our findings contrast with the findings of Holden (10) who evaluated 35 colloid nodules and found the majority were avascular. Our findings are also contrary to Gannon et al. (11) who evaluated 236 nodules and found absence of flow was a feature "most consistent with benign nodules". In addition, other authors reached the conclusion that an avascular nodule is not likely to be malignant (12-14). Our findings validate that an avascular nodule can be malignant.

In our study, perinodular flow only was equally as common in colloid nodules (15\%) as in PTC $(16 \%)$, and this was not significantly different both without or with an adjusting for nodular size $(\mathrm{P}>0.05)$. In addition, the nodules that demonstrated both intranodular and perinodular flow were greater in the colloid group (34\%) than the PTC group (26\%). However, this was also not significantly different both without and with an adjustment for nodule size $(\mathrm{P}>0.05)$. These findings contradict those of other authors $(15,16)$ who concluded that perinodular Doppler flow is a feature of benign thyroid nodules. However, our findings are similar to those of authors $(12-14,17)$ who found that perinodular flow can be present in malignant nodules.

Intranodular flow was noted in $61 \%$ of PTC cases when combining those without $(53 / 166)$ and with perinodular flow (43/166) and those with diffuse flow (6/166). This is consistent with previous studies in the literature that describe rates of intranodular flow in malignant thyroid nodules ranging from $6 \%$ to $74 \%(1,3,10,12,16-23)$. Several prior studies showed that intranodular flow was more common in malignant nodules $(3,19,21)$ while others showed the opposite finding $(15,20,24-26)$. The rate of intranodular flow in colloid nodules (70\%) when compared with PTC (61\%) in our study was higher, but not significant $(\mathrm{P}>0.05)$ and remained insignificant after adjusting for nodular size $(\mathrm{P}>0.05)$. This held true using multiple logistic regression with intranodular flow as the reference standard. We used intranodular flow as the reference standard because this category was the largest sample size and was in the middle of the range between no flow and diffuse flow which would reduce standard error.

Anil et al. (16) found that the presence of "chaotic intranodular vascularity" was an US feature of malignant lesions. We found that diffuse flow occurred more often in colloid nodules (7\%) than PTC (4\%). However, this was also not significantly different even when adjusting for 

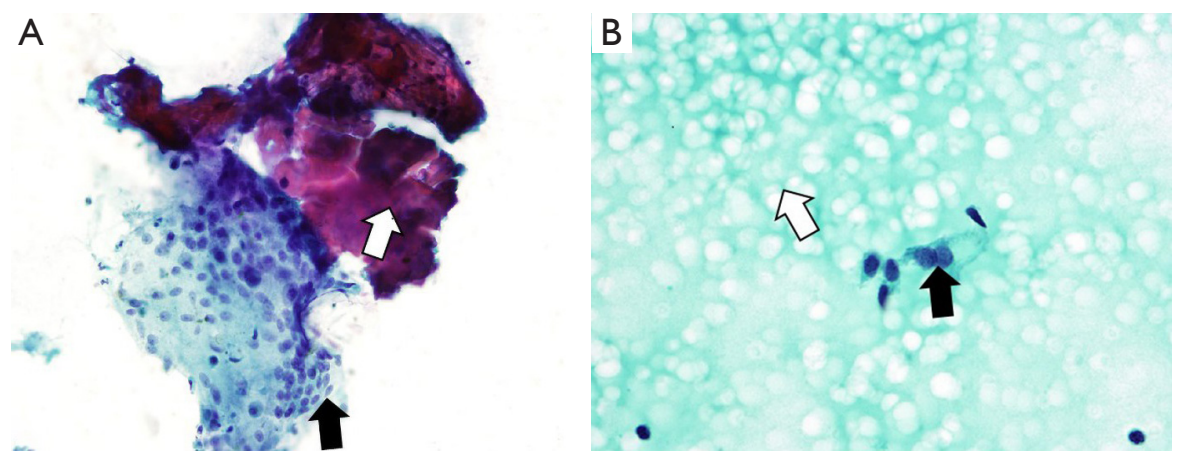

Figure 1 Illustration of fine needle aspiration biopsy findings of a colloid nodule showing (A) (Papanicolaou stain, $\times 100)$ a fragment of inspissated colloid (white arrow) associated with a multinucleated foreign body giant cell (black arrow) and (B) (Papanicolaou stain, $\times 100$ ) abundant thin watery colloid (white arrow) with few benign thyroid follicular cells (black arrow).

nodule size $(\mathrm{P}>0.05)$.

To the best of our knowledge, this study is the first to demonstrate that the majority of cytopathologically-proven colloid nodules may have intranodular vascular flow, and the first study to adjust for nodular size and show similar findings. It is also the first study to show that nodules with colloid and PTC do not demonstrate significant differences in vascular flow patterns with an adjustment for size. As a result, we concur with the conclusion of prior studies suggesting that intranodular flow should not be used to assess the risk of thyroid malignancy $(15,20,24,27-29)$.

In our study, $70 \%$ of colloid nodules demonstrated central vascular flow. The thyroid gland contains follicles that are lined by follicular cells and filled with colloid that contains thyroglobulin. In response to signals indicating that thyroid hormones are needed, the follicular cells reabsorb thyroglobulin from the colloid. Enzymes in the follicular cells then split thyroglobulin and release thyroxine and triiodothyronine into the circulation. Excessive storage of colloid causes the nodule to become enlarged with flattening of the epithelium (Figure 1). Colloid nodules may be single or multiple, vary considerably in size, and can occur as a cystic nodule or a solid nodule with regions of hemorrhage, necrosis, and/or calcification $(30,31)$. Larger colloid nodules have been described to have internal vascularization within areas of follicular proliferation (32). Interestingly, our results showed no difference in the any of the vascular flow patterns and no relation to size. The positive skew of the size data for all flow categories of colloid nodules shows that the nodules in the other categories tended to be smaller with the larger nodules as outliers in our study group. This suggests that internal vascularization is present in smaller colloid nodules and that perhaps this flow can now be detected in smaller nodules with improved US technology (33).

PTC is a well-differentiated tumor and the most common thyroid malignancy. Most cases of PTC are easily diagnosed with FNA and cytologic evaluation. However, approximately $20 \%$ of specimens are nondiagnostic because of a lack of or paucity of nuclear features suggestive of PTC. Biopsy specimens of PTC show a wide range of cytological findings, usually high cellularity with scant colloid. The epithelium of PTC is usually arranged as syncytial fragments. Pleomorphism with enlargement and crowding of the nuclei with nuclear grooves and intranuclear cytoplasmic inclusions is diagnostic (Figure 2) (34-36). Studies have correlated vascularity with malignancy that is related to the cellular proliferation $(37,38)$ however, a study by Wienke et al. (27) did not find a similar correlation. Our results similar to those of Wienke et al. as there is no difference in the vascular flow patterns between colloid nodules and PTC even after an adjustment for size.

Limitations of the study include the retrospective review and that only cytopathologically-proven colloid nodules and PTC were compared. A future study could compare the flow characteristics of colloid nodules to other types of thyroid cancer including follicular thyroid carcinoma (39).

In conclusion this study demonstrates that both colloid nodules and PTC can present with intranodular and/or perinodular vascular flow. Contrary to prior reports in the literature, our study suggests that the presence or absence of intranodular or perinodular vascular flow may not be a reliably predictor of colloid nodules versus PTC. As a result, we advise against the use of vascularity in assessing the risk of PTC. 

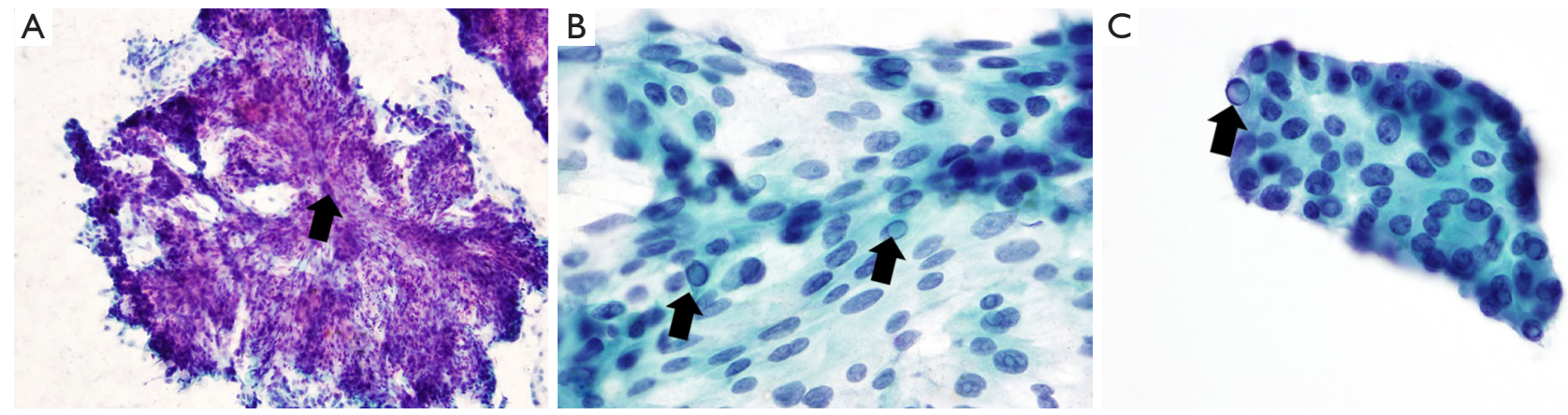

Figure 2 Illustration of fine needle aspiration biopsy findings in a case of papillary thyroid carcinoma showing (A) (Papanicolaou stain, $\times 100$ ) papillae with underlying prominent fibrovascular cores (arrow); (B,C) (Papanicolaou stain, $\times 200)$ the tumor cells show characteristic nuclear features of PTC with enlarged oval nucleus, open nuclear chromatin including nuclear grooves and few intranuclear inclusions (arrows).

\section{Acknowledgments}

Funding: The University of Texas MD Anderson Cancer Center is supported in part by the National Institutes of Health through Cancer Center Support Grant CA016672.

\section{Footnote}

Conflicts of Interest: The authors have no conflicts of interest to declare.

Ethical Statement: The authors are accountable for all aspects of the work in ensuring that questions related to the accuracy or integrity of any part of the work are appropriately investigated and resolved. The Institutional Review Board of The University of Texas MD Anderson Cancer Center approved this study (No. PA12-1154) and waived the requirement for informed consent. Data review was performed in compliance with all applicable Health Insurance Portability and Accountability Act regulations.

\section{References}

1. Frates MC, Benson CB, Charboneau JW, et al. Management of thyroid nodules detected at US: Society of Radiologists in Ultrasound consensus conference statement. Radiology 2005;237:794-800.

2. Marqusee E, Benson CB, Frates MC, et al. Usefulness of ultrasonography in the management of nodular thyroid disease. Ann Intern Med 2000;133:696-700.

3. Papini E, Guglielmi R, Bianchini A, et al. Risk of malignancy in nonpalpable thyroid nodules: predictive value of ultrasound and color-Doppler features. J Clin
Endocrinol Metab 2002;87:1941-6.

4. Choi SH, Kim EK, Kwak JY, et al. Interobserver and intraobserver variations in ultrasound assessment of thyroid nodules. Thyroid 2010;20:167-72.

5. Hwang HS, Orloff LA. Efficacy of preoperative neck ultrasound in the detection of cervical lymph node metastasis from thyroid cancer. Laryngoscope 2011;121:487-91.

6. Smith RB, Evasovich M, Girod DA, et al. Ultrasound for localization in primary hyperparathyroidism. Otolaryngol Head Neck Surg 2013;149:366-71.

7. Haugen BR, Alexander EK, Bible KC, et al. 2015 American Thyroid Association Management Guidelines for Adult Patients with Thyroid Nodules and Differentiated Thyroid Cancer: The American Thyroid Association Guidelines Task Force on Thyroid Nodules and Differentiated Thyroid Cancer. Thyroid 2016;26:1-133.

8. Lee MJ, Kim EK, Kwak JY, et al. Partially cystic thyroid nodules on ultrasound: probability of malignancy and sonographic differentiation. Thyroid 2009;19:341-6.

9. Kim DW, Lee EJ, In HS, et al. Sonographic differentiation of partially cystic thyroid nodules: a prospective study. AJNR Am J Neuroradiol 2010:31:1961-6.

10. Holden A. The role of colour and duplex Doppler ultrasound in the assessment of thyroid nodules. Australas Radiol 1995;39:343-9.

11. Gannon AW, Langer JE, Bellah R, et al. Diagnostic Accuracy of Ultrasound With Color Flow Doppler in Children With Thyroid Nodules.J Clin Endocrinol Metab 2018;103:1958-65.

12. Chan BK, Desser TS, McDougall IR, et al. Common and uncommon sonographic features of papillary thyroid carcinoma. J Ultrasound Med 2003;22:1083-90.

13. Solbiati L, Charboneau JW, Osti V, et al. The thyroid 
gland. In: Rumack CM, Wilson SR, Charboneau JW. editors. Diagnostic Ultrasound 3rd ed. Vol. 1. St. Louis, Missouri: Elsevier Mosby; 2005:735-70.

14. Hoang JK, Lee WK, Lee M, et al. US Features of thyroid malignancy: Pearls and pitfalls. Radiographics 2007;27:847-60.

15. Andrioli M, Chiara Carzaniga C, Luca Persani L. Standardized Ultrasound Report for Thyroid Nodules: The Endocrinologist's Viewpoint. Eur Thyroid J 2013;2:37-48.

16. Anil G, Hegde A, Chong FH. Thyroid nodules: risk stratification for malignancy with ultrasound and guided biopsy. Cancer Imaging 2011;11:209-23.

17. Fu X, Guo L, Zhang H, et al. "Focal thyroid inferno" on color Doppler ultrasonography: a specific feature of focal Hashimoto's thyroiditis. Eur J Radiol 2012;81:3319-25.

18. Iannuccilli JD, Cronan JJ, Monchik JM. Risk for malignancy of thyroid nodules as assessed by sonographic criteria: the need for biopsy. J Ultrasound Med 2004;23:1455-64.

19. Lyshchik A, Moses R, Barnes SL, et al. Quantitative analysis of tumor vascularity in benign and malignant solid thyroid nodules. J Ultrasound Med 2007;26:837-46.

20. Kim HG, Moon HJ, Kwak JY, et al. Diagnostic accuracy of the ultrasonographic features for subcentimeter thyroid nodules suggested by the revised American Thyroid Association guidelines. Thyroid 2013;23:1583-9.

21. Brunese L, Romeo A, Iorio S, et al. A new marker for diagnosis of thyroid papillary cancer: B-flow twinkling sign. J Ultrasound Med 2008;27:1187-94.

22. Yuan WH, Chiou HJ, Chou YH, et al. Gray-scale and color Doppler ultrasonographic manifestations of papillary thyroid carcinoma: analysis of 51 cases. Clin Imaging 2006;30:394-401.

23. Tamsel S, Demirpolat G, Erdogan M, et al. Power Doppler US patterns of vascularity and spectral Doppler US parameters in predicting malignancy in thyroid nodules. Clin Radiol 2007;62:245-51.

24. Stacul F, Bertolotto M, De Gobbis F, et al. US, colourDoppler US and fine-needle aspiration biopsy in the diagnosis of thyroid nodules. Radiol Med 2007;112:751-62.

25. Khadra H, Bakeer $M$, Hauch A, et al. Is vascular flow a predictor of malignant thyroid nodules? A meta-analysis. Gland Surg 2016;5:576-82.

26. Rosario PW, Silva AL, Borges MA, et al. Is Doppler ultrasound of additional value to gray-scale ultrasound in differentiating malignant and benign thyroid nodules? Arch Endocrinol Metab 2015;59:79-83.

27. Wienke JR, Chong WK, Fielding JR, et al. Sonographic features of benign thyroid nodules: interobserver reliability and overlap with malignancy. J Ultrasound Med
2003;22:1027-31.

28. Wu MH, Chen CN, Chen KY, et al. Quantitative analysis of dynamic power Doppler sonograms for patients with thyroid nodules. Ultrasound Med Biol 2013;39:1543-51.

29. Moon HJ, Kwak JY, Kim MJ, et al. Can vascularity at power Doppler US help predict thyroid malignancy? Radiology 2010;255:260-9.

30. Salabè GB. Pathogenesis of thyroid nodules: histological classification? Biomed Pharmacother 2001;55:39-53.

31. Ramelli F, Studer H, Bruggisser D. Pathogenesis of thyroid nodules in multinodular goiter. Am J Pathol 1982;109:215-23.

32. Foschini MP, Ragazzi M, Parmeggiani AL, et al. Comparison between echo-color Doppler sonography features and angioarchitecture of thyroid nodules. Int J Surg Pathol 2007;15:135-42.

33. Cerbone G, Spiezia S, Colao A, et al. Power Doppler improves the diagnostic accuracy of color Doppler ultrasonography in cold thyroid nodules: follow-up results. Horm Res 1999;52:19-24.

34. Baloch ZW, LiVolsi VA. Fine-needle aspiration of thyroid nodules: past, present, and future. Endocr. Pract 2004;10:234-41.

35. Baloch ZW, Sack MJ, Yu GH, et al. Fine-needle aspiration of thyroid: an institutional experience. Thyroid 1998;8:565-9.

36. Goellner JR, Gharib H, Grant CS, et al. Fine needle aspiration cytology of the thyroid. Acta Cytol 1987;31:587-90.

37. Brito JP, Gionfriddo MR, Al Nofal A, et al. The accuracy of thyroid nodule ultrasound to predict thyroid cancer: systematic review and meta-analysis. J Clin Endocrinol Metab 2014;99:1253-63.

38. Cappelli C, Castellano M, Pirola I, et al. The predictive value of ultrasound findings in the management of thyroid nodules. QJM 2007;100:29-35.

39. Yang GCH, Fried KO. Most Thyroid Cancers Detected by Sonography Lack Intranodular Vascularity on Color Doppler Imaging: Review of the Literature and Sonographic-Pathologic Correlations for 698 Thyroid Neoplasms. J Ultrasound Med 2017;36:89-94.

Cite this article as: Debnam JM, Vu T, Sun J, Wei W, Krishnamurthy S, Zafereo ME, Weitzman SP, Garg N, Ahmed S. Vascular flow on doppler sonography may not be a valid characteristic to distinguish colloid nodules from papillary thyroid carcinoma even when accounting for nodular size. Gland Surg 2019;8(5):461-468. doi: 10.21037/gs.2019.08.06 